\title{
VERIFICATION OF RAM-PRESS PIPE BENDING PROCESS USING ELASTO-PLASTIC FEM MODEL
}

\author{
Paweł SIDUN*, Andrzej ŁUKASZEWICZ
}

${ }^{*}$ Faculty of Mechanical Engineering, Bialystok University of Technology, 45C Wiejska Street, 15-351 Bialystok, Poland

pawel.sidun@gmail.com, a.lukaszewicz@pb.edu.pl

received 6 February 2016, revised 27 February 2017, accepted 6 March 2017

\begin{abstract}
In this paper selected aspects of numerical modelling of bending pipes process are described. Elasto-plastic material model was used in COMSOL FEM environment. The results of numerical analyses of two kinds of steel were presented. The correctness of the proposed model was verified based on comparison shapes of deformed pipe profile obtained at the ending step of bending both from numerical simulations and experiment.
\end{abstract}

Key words: Pipe Bending, FEM Analysis

\section{INTRODUCTION}

Bending pipe technology is used in many branches of industry. Development of Computer Aided Engineering (CAE) systems allows for numerical analysis of bending pipe phenomena in many different approaches. The research work (Kuanget al., 2015) presented numerical analysis of thermoplastic pipes under external pressure and bending moment. The research paper (Dong et al., 2015) showed analytical and numerical approach of biaxial dynamic unbounded flexible pipe bending process. Some analytical and numerical aspects of plastic limit loads for pipe under combined loading condition presented Haoet al. (2016) and Li et al. (2015). Problem of wrinkling carbon steel pipes using a numerical approach was solved by Vasilikis and Karamanos (2012). Effect of using different boundary conditions for bending pipe process in finite elements modelling was presented by Guarracino et al. (2008). Stress analysis of composite pipes during bending process in analytical approach presented Menshykova et al. (2014). Dong et al. (2015) reported another analytical approach for unbounded flexible pipe during bending process.

Presented short literature review shows many different approaches for modelling bending pipe process. Industry still needs easy way to evaluate many factors of bending process like ovalization and degree of bending after springback of material for optimization bending process (e.g. in CNC bending pipe machines). The aim of this paper is to present a 3D elasto-plastic FEM model of ram-press bending process, created in COMSOL software, and its verification by compare shapes of deformed cross-sections of pipe obtained from numerical analysis and experimental tests.

\section{FINITE ELEMENT ANALYSIS OF RAM-PRESS BENDING PROCESS}

In this paper numerical analysis of ram-press bending process (Korzemski, 1971) was presented (Fig. 1). Finite Element Method (FEM) analysis with elasto-plastic model, using COMSOL Mul- tiphysic environment, was used. Experimental test of bending was done for pipe with dimension $\phi 16 \times 2$ made of structural steel E235+N. Total displacement of pattern for bending process used in experiment was $120 \mathrm{~mm}$, the direction of pattern determines force $P$ and the same value was applied in numerical analysis (Sidun, 2015). FEM analysis was based on data of stress-stain curve for three types of steel (stainless steel 1.4313, structural steel Kodur 260MC and E235+N). These was obtained from tension test of specimens cut from pipe and next implemented to elasto-plastic model in FEM system (Fig. 2, 3, 4).

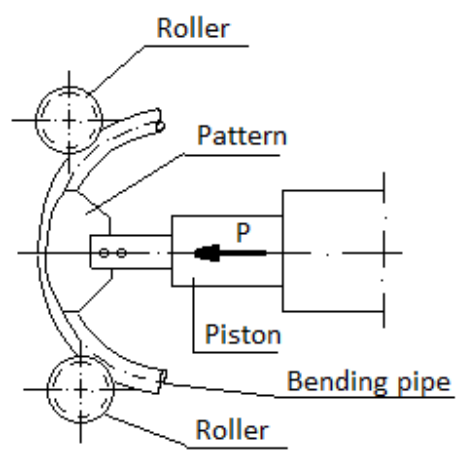

Fig. 1. Scheme of analysed bending process

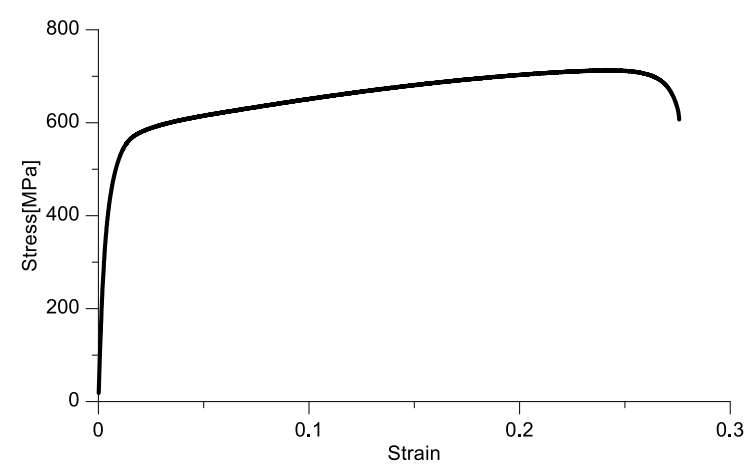

Fig. 2. Stress-strain curve from tension test for steel 1.4313 


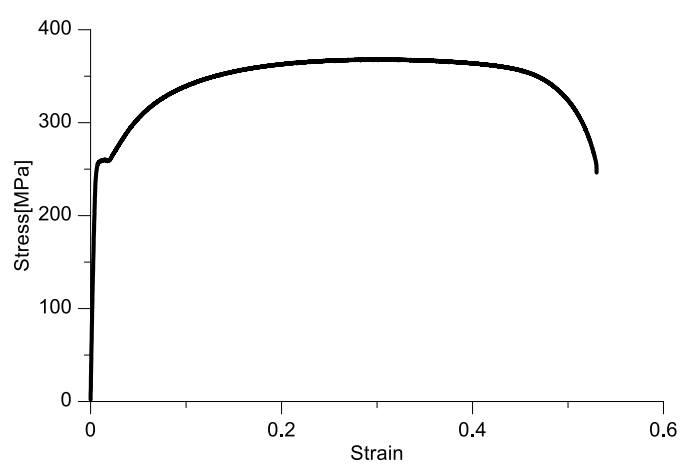

Fig. 3. Stress-strain curve from tension test for Kodur 260MC steel

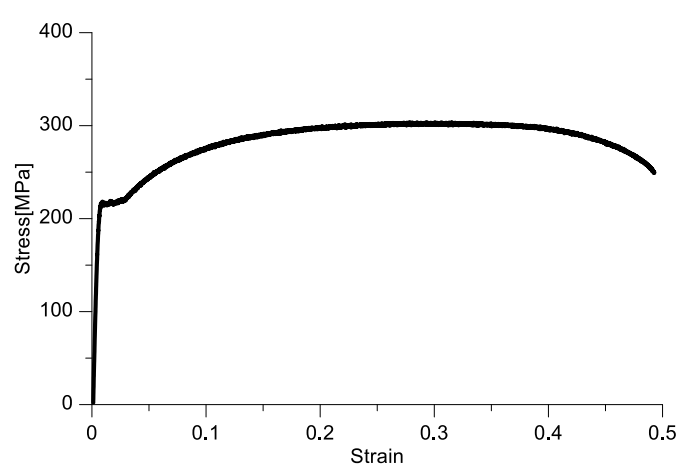

Fig. 4. Stress-strain curve from tension test for steel E235+N

Elasto-plastic FEM model was based on Huber-Mises yield criterion and isotropic hardening model of material (Ottosen and Ristinmaa, 2005). Contact between elements in FEM analysis was defined in following way: the roller and the pattern are rigid, the pipe has elasto-plastic behaviour, contact for pairs (roller-pipe and pattern-pipe) is assumed without friction coefficient.

In FEM system symmetry conditions (Fig. 5) were applied. Following boundary conditions (see coordinate system) were used (Fig. 5).

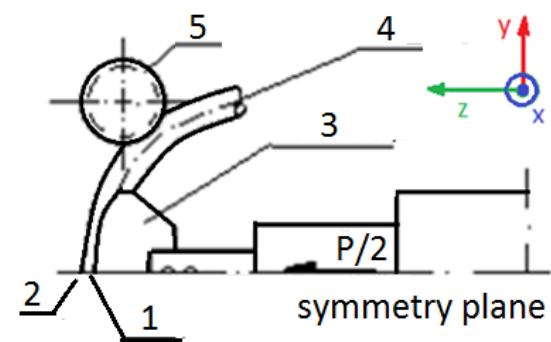

Fig. 5. Definition of boundary conditions ( $1-$ face of pipe in symmetry line has $u_{y}=0 ; 2-$ external point of pipe in symmetry line has $u_{x}=0$; 3 - pattern can only move in $z$ axis; 4 - pipe, have all degree of freedom, 5 - roller can only rotate about $x$ axis)

Discrete model of ram-press bending components was made using quad elements to build the pattern and the pipe and tetra elements to build the roller (Fig. 6). Number degree of freedom brought 434723 .

The main advantage of application FEM analysis in bending pipe process is faster implementation time of new series of products. Numerical analysis of bending pipe process allows for continuous productions process with reason of preparation initial bending parameters to obtain good quality of final product.
It is very important because eliminates errors of bending radius due to springback and allows to predict good results of shape deformations.

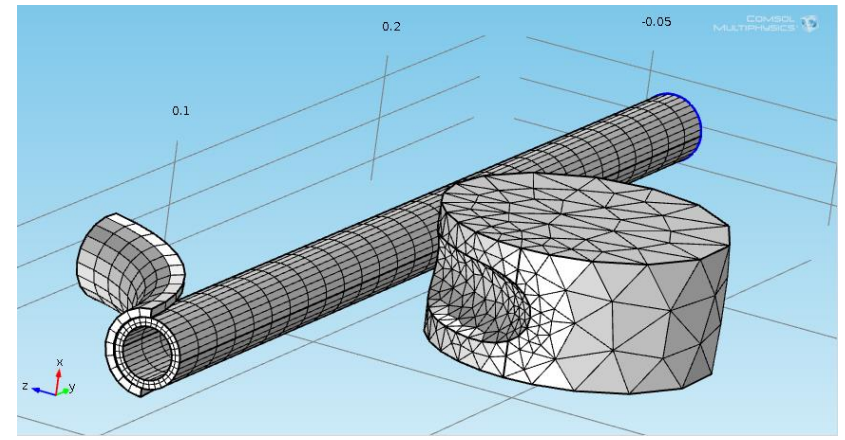

Fig 6. 3D mesh of ram-press bending FEM model in COMSOL Multyphysics

\section{MAP OF EFFECTIVE PLASITC STRAIN FOR DIFFERENT MATERIALS}

Analysis was executed for three materials: 1 - stainless steel 1.4313 (SS) designated for manufacture of parts and components for machines such as parts of pumps, compressors and turbines, 2 - steel Kodur 260MC used to produce welding constructions, pressure tank, pipelines, chassis of car, 3 - structural steel $\mathrm{E} 235+\mathrm{N}$ used to produce pipes, chassis of car, pumps compressors. The results of numerical analysis of ram-press bending pipe process show dependency between material plastic behaviour (strain-stress curve) and received deformation (effective plastic strain).

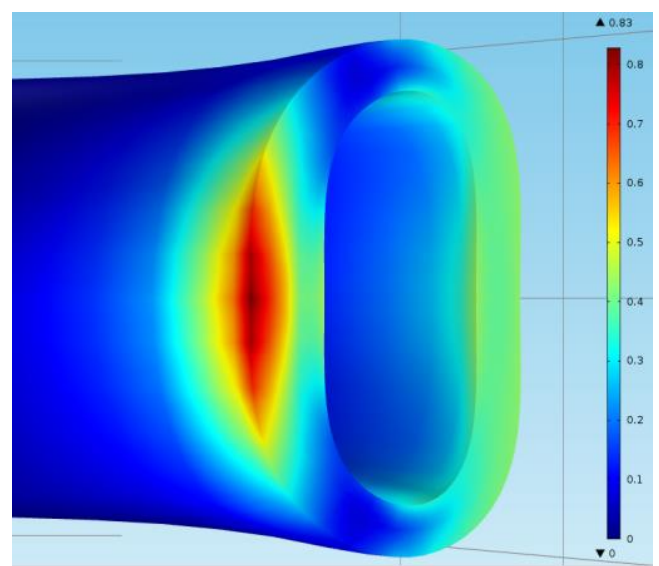

Fig. 7. Map of effective plastic strain for steel 1.4313

Figures 7, 8 and 9 present deformations of profile in the symmetry plane at the ending step of loading. Structural steel Kodur 260MC (Fig. 8) and E235+N (Fig. 9) steel demonstrate almost exactly the same deformation of bending profile. Stainless steel 1.4313 (Fig. 7) has flatten of pipe profile what is unacceptable in pipe bending process. In this case obtained value of effective plastic strain is much greater than real maximum strain $(0,25)$ before plastic fracture (Fig. 2). It means, for this steel, fracture can occur after the strain exceeded limit value about 0,25 . In computational process a real behaviour of material including fracture mechanism was not defined. FEM system continues calculations, 
for the maximum stress value declared in strain-stress curve, to the end step of bending. That initial analysis of deformation profile helps in preliminary analysis of suitability materials for the bending process.

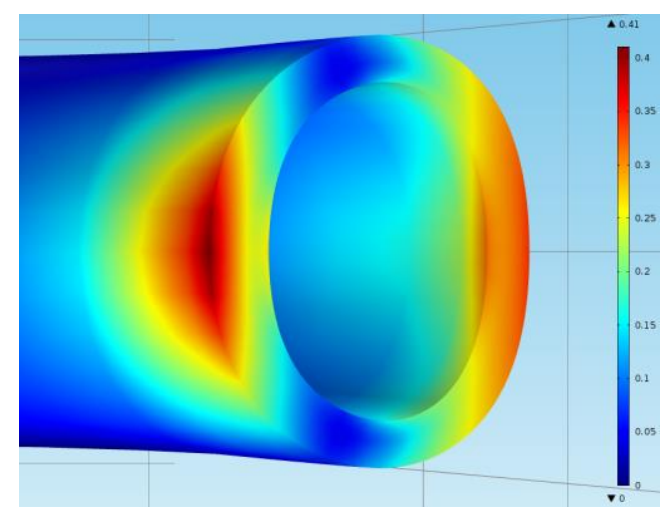

Fig. 8. Map of effective plastic strain for Kodur260MC steel

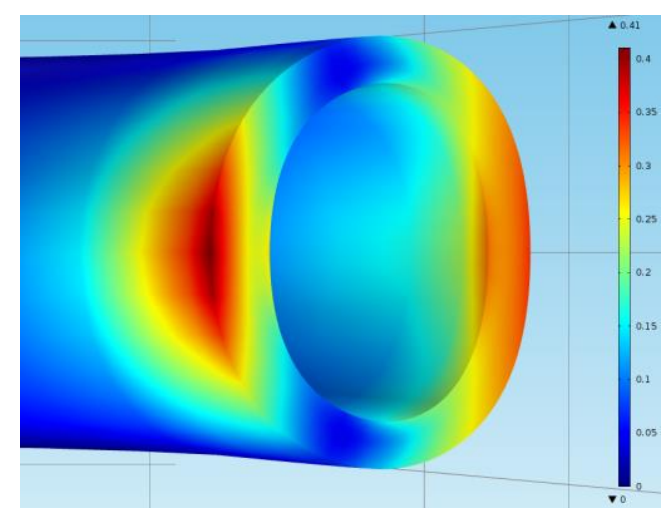

Fig. 9. Map of effective plastic strain for steel E235+N

\section{EVOLUTION OF STRESS AND STRAIN DURING BENDING PROCESS}

During ram-press bending process pipe zones were subjected to different stress conditions. The most loaded points of pipe presents Fig. 10.

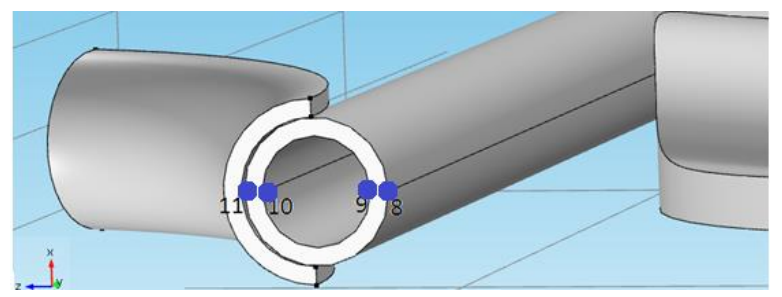

Fig. 10. Points of measure stress and strain during bending process

Pipe was under two different state of loading: compression line 10 and 11 , tension - 8 and 9, for stainless steel 1.4313 (Fig. 11, 12), Kodur 260MC steel (Fig. 13, 14) and E235+N (Fig. 15, 16).

Graphs (Fig. 11, 13, 15) show that material was subjected almost the same compressive stress in points 11 and 10 . Points 8 and 9 shows that material was more loaded in inside part of pipe. Difference in Huber-Von-Misses stress for steel Kodur260MC and $\mathrm{E} 235+\mathrm{N}$ is very small, what is caused by almost exactly the same characteristic of strain-stress curve. Steel 1.4313 has very big difference in stress between points 9 and 8 , what is caused by thinning of inside part of pipe.

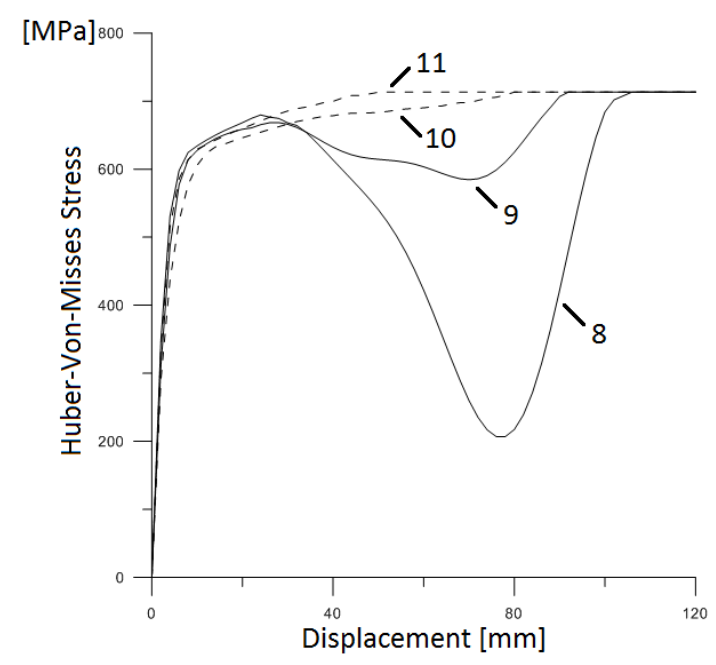

Fig. 11. Evolution of Huber-Von-Misses stress during bending process for stainless steel 1.4313

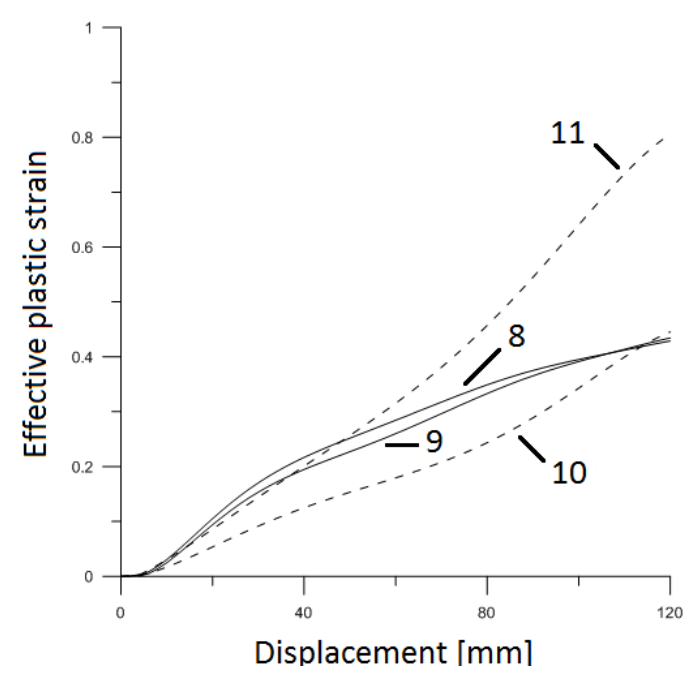

Fig. 12. Evolution of effective plastic strain during bending process for stainless steel 1.4313

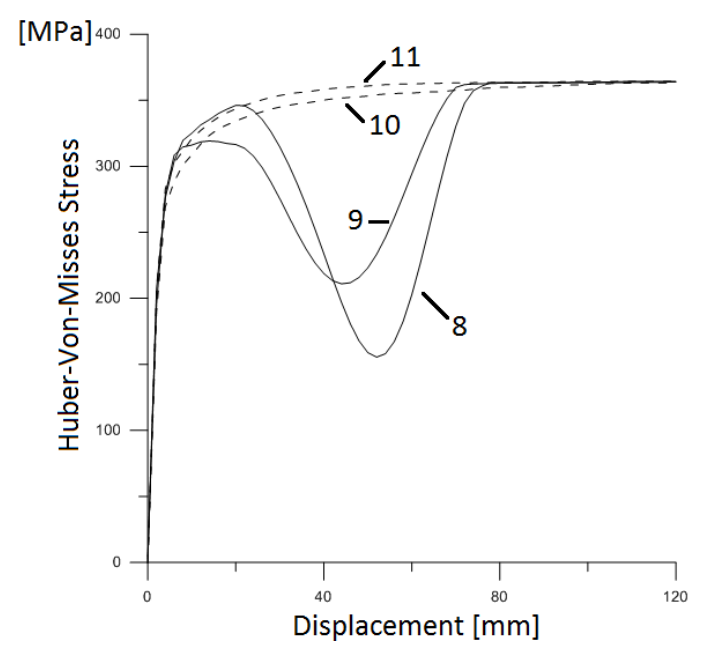

Fig. 13. Evolution of Huber-Von-Misses stress during bending process for Kodur 260MC steel 


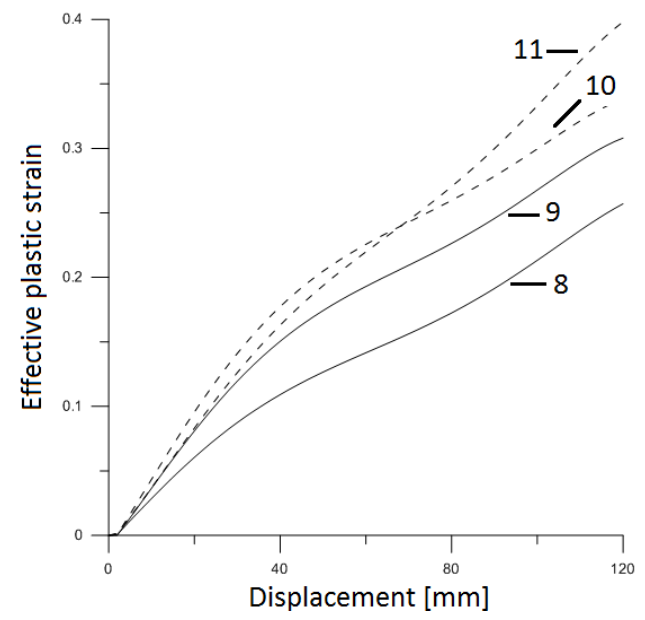

Fig. 14. Evolution of effective plastic strain during bending process for Kodur 260MC steel

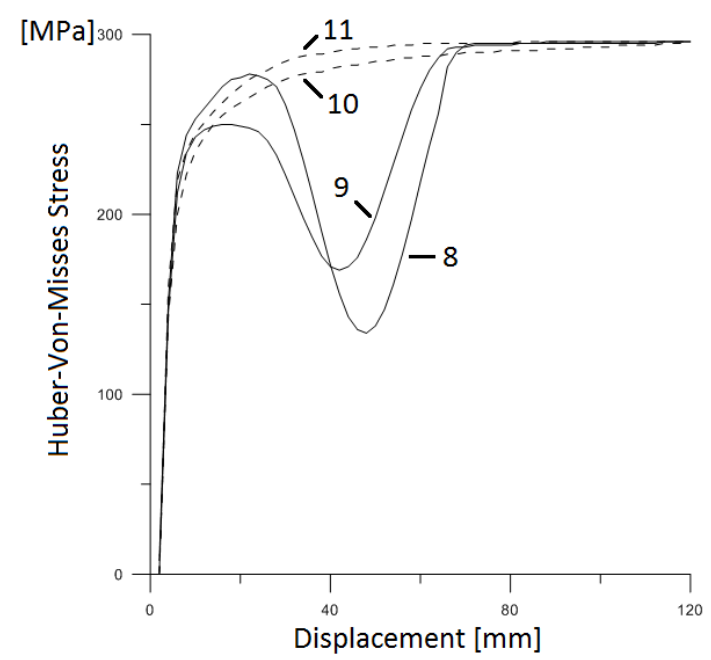

Fig. 15. Evolution of Huber-Von-Misses stress during bending process for steel $\mathrm{E} 235+\mathrm{N}$

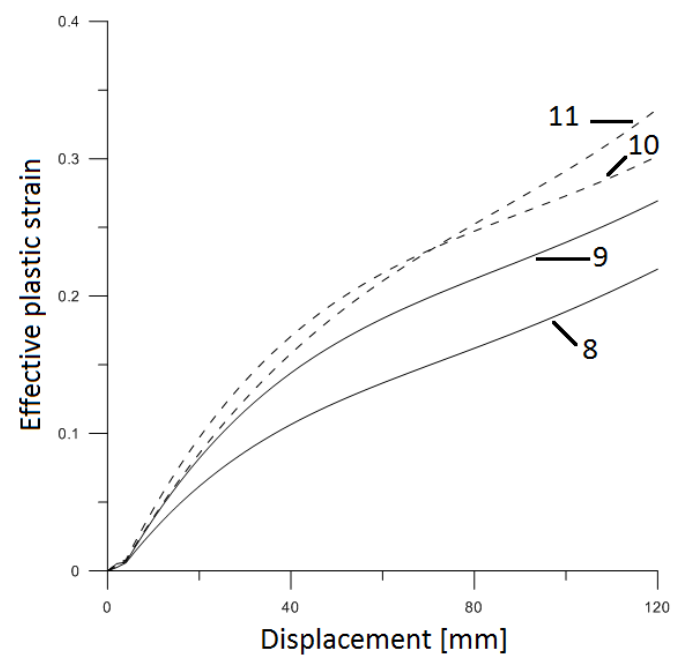

Fig. 16. Evolution of effective plastic strain during bending process for steel $\mathrm{E} 235+\mathrm{N}$

Fig. 12 presents evolution of effective plastic strain during bending process for steel 1.4313. Lines 8 and 9 show that tensioned points of pipe have similar behaviour of plastic strain. Lines
10 and 11 demonstrate that outside part (point 10) of the pipe was more compressed that inside (point 11).

Fig.14 shows evolution of effective plastic strain for Kodur 260MC steel. Line 10, 9 and 8 have similar characteristic of growth strain. Character of line 11 is different what can be caused by thickening of inside wall of pipe.

Fig. 16 presents evolution of effective plastic strain for steel E235+N with similar characteristic of growth strain with Fig. 14 . Different between this two graph is that for steel $\mathrm{E} 235+\mathrm{N}$ extreme compressed and tensile fibers was load with the same force. Received deformation of profile presents Fig 9 .

Summarize received results, small change of characteristic strain-stress curve in FEM analysis cause very significant course of evolution effective plastic strain. In Huber-Von-Misses stress that effect not observed. Also for steel 1.4313 observed exceed of maximal value stress and strain. Based on Fig 11 and 12 we can establish maximal protrusion of pattern what not cause undulation in point of largest compressive stress concentration.

\section{RESULTS OF VERIFICATION}

The results of deformed shapes obtained from experiment and simulation for steel E235+N are presented in Fig. 17. Planar profile from Fig. 17 was created using $2 D$ CAD tools and compared (Fig. 18). Fig. 19 presents radius of bending $R$ and bending angle $\alpha$.

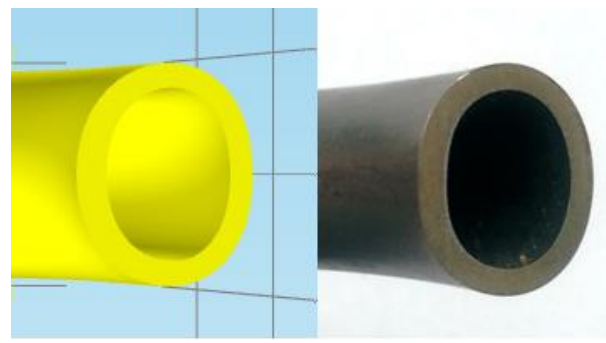

Fig. 17. Results of deformed shapes of pipe obtained from numerical and experimental analyses

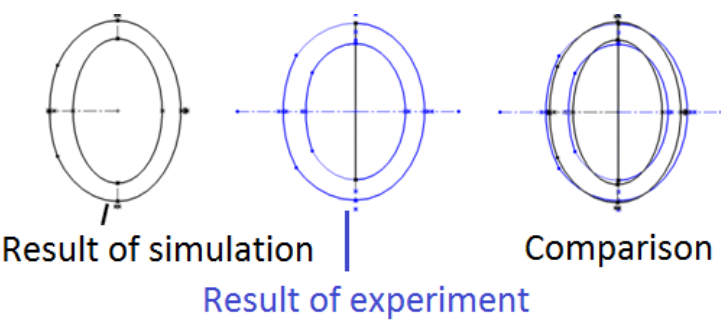

Fig. 18. Results of numerical and experimental analyses

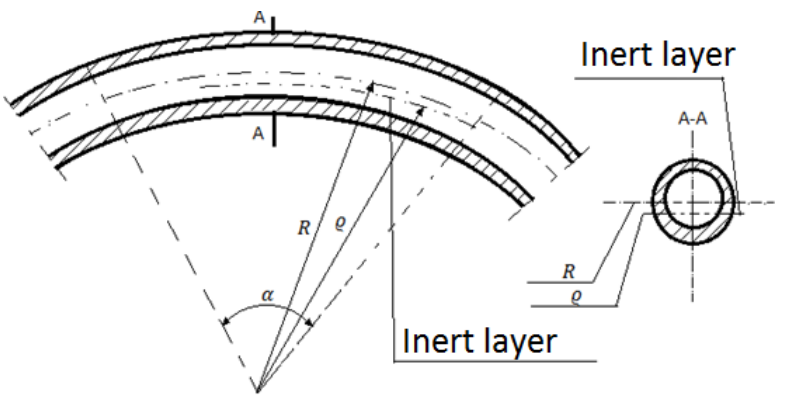

Fig. 19. Bending values during bending pipe process 


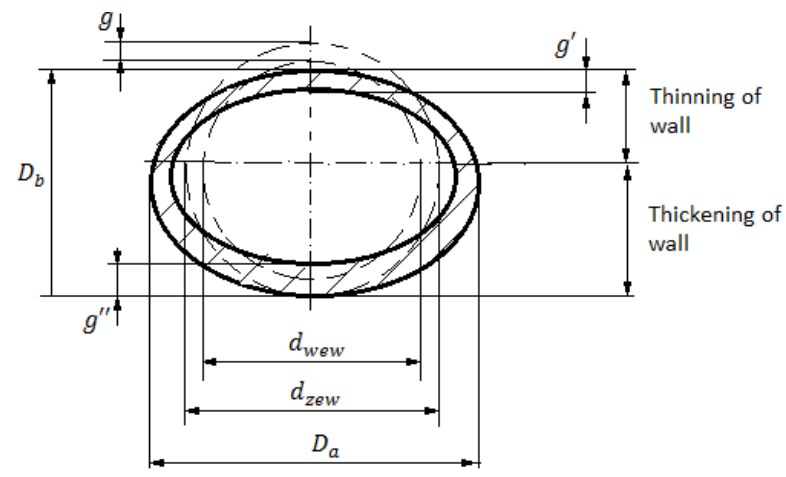

Fig. 20. Deformation of the pipe cross-section during bending

Parameters of deformations during bending pipe process presents Fig. 20. Based on bending parameters from Fig. 20 we can compute two most important parameters of bending pipe process, roundness (1) and relative bending radius (2).

Roundness:

$e=\frac{D_{a}-D_{b}}{d_{\text {zew }}}$.

Relative bending radius:

$r=\frac{R}{d_{z e w}}$.

This two parameters of bending pipes are normalized for pipes transporting different medium. Small roundness and well matched relative bending radius cause less flow of liquid. Normally this two parameters are selected based on preliminary test bending. The new approach for determination that parameters is FEM analysis of bending pipe process. Comparison of shape parameters obtained from experimental and numerical tests presents Tab. 1.

Tab. 1. Values of numerical and experimental analyses

\begin{tabular}{|c|c|c|c|}
\hline $\begin{array}{l}\text { Parameter } \\
\text { of bending }\end{array}$ & $\begin{array}{c}\text { Value } \\
\text { of parameter } \\
\text { received } \\
\text { experimentally }\end{array}$ & $\begin{array}{c}\text { Value } \\
\text { of parameter } \\
\text { received form } \\
\text { simulation }\end{array}$ & $\begin{array}{c}\text { Relative } \\
\text { error } \\
{[\%]}\end{array}$ \\
\hline $\begin{array}{l}D_{a} \text { major axis } \\
\text { of the ellipse }[\mathrm{mm}]\end{array}$ & 17 & 17.5 & 2.8 \\
\hline $\begin{array}{l}D_{b} \text { minor axis } \\
\text { of the ellipse [mm] }\end{array}$ & 14 & 13.5 & 3.5 \\
\hline Roundness [\%] & 18.7 & 25 & 25.2 \\
\hline Thinning of wall [mm] & 1.8 & 1.7 & 5.5 \\
\hline $\begin{array}{l}\text { Thickening of wall } \\
\text { [mm] }\end{array}$ & 2.1 & 2.2 & 4.5 \\
\hline
\end{tabular}

Analysing values of shape parameters show that in four cases the relative error of parameters don't exceed $10 \%$. This four results testifies about that Comsol elasto-plastic module is a good tool for analysing bending pipe process. Roundness normally don't exceed $10 \%$ but in this case, main idea was to show deformation seen with naked eye, so received results are out of values in accepted standards. In normal conditions of bending pipes process, roundness is very important parameter for pipes working in higher pressure because determines corrosion resistance in grain boundaries caused by micro-cracks in places of thickening wall emerging under bending pipe process.

\section{SPRINGBACK OF PIPE AFTER BENDING PROCESS}

The most important problem in CNC bending pipe process is still springback after bending. There is many approach to solve that problem. The scientific papers (Zhao et al., 2011; Zhao et al., 2014) present some analytical and numerical solutions for springback in bending plate and pipe processes. The hot bending pipe process is also solved (Hu,1998) using an analytical approach. The simple idea of solving this problems FEM analysis in Comsol environment which deal with that problem with very good results. Received results taken from experiment of bending angle after springback was about $70^{\circ}$. Results of simulations present Fig. 21, 22 and 23.

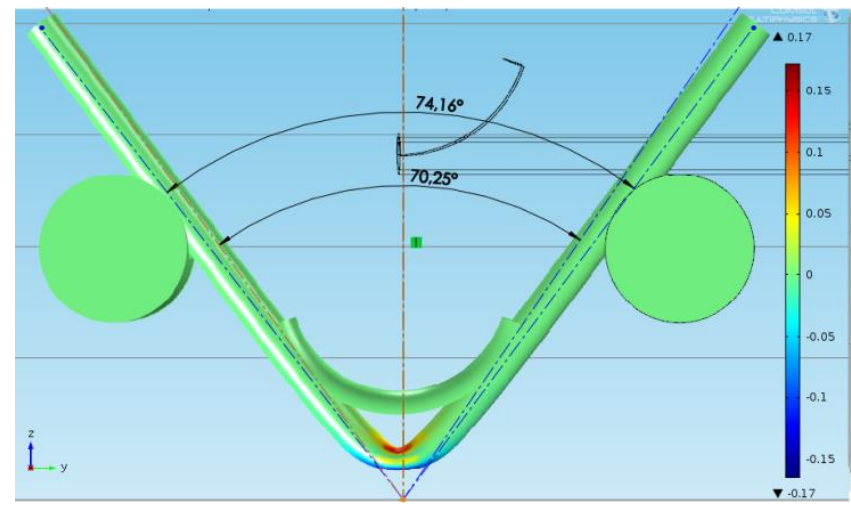

Fig. 21. Springback after bending pipe for steel 1.4313

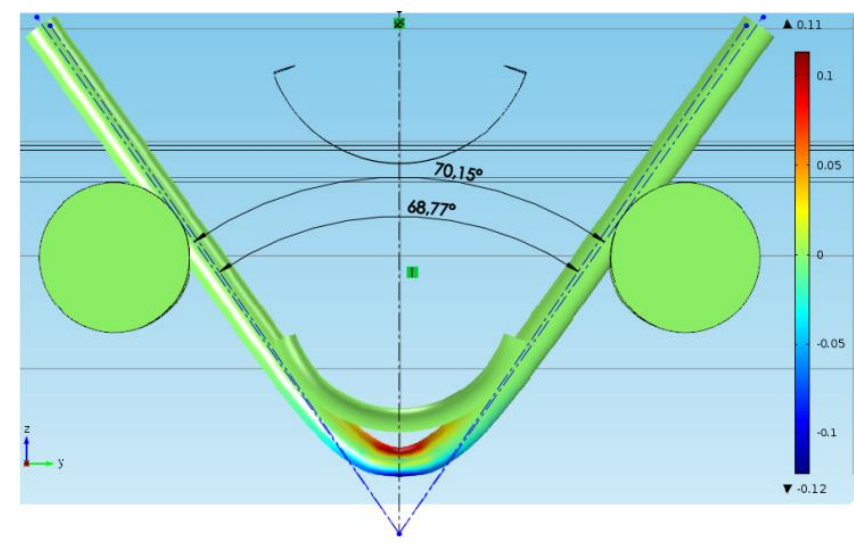

Fig. 22. Springback after bending pipe for steel Kodur 260MC

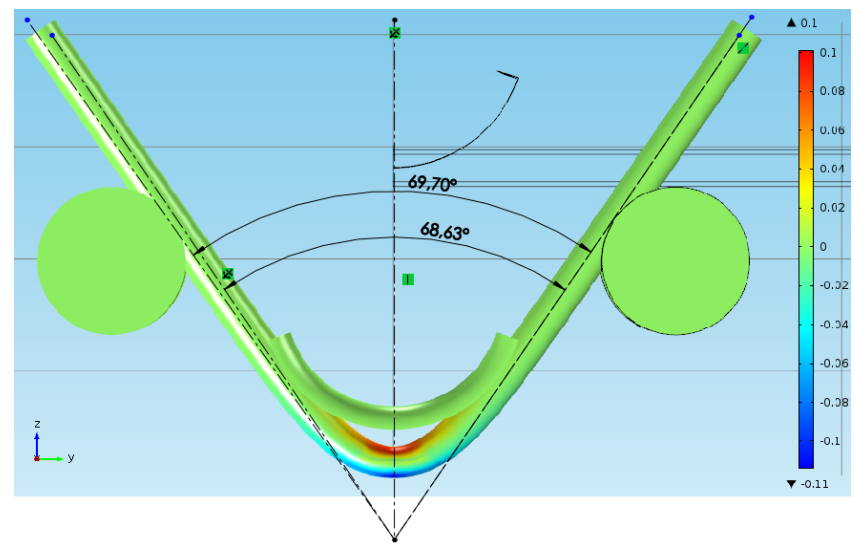

Fig. 23. Springback after bending pipe for steel E235+N 
The results of simulation shows Tab. 2. Degree of bending was measured between two axes of symmetry bending pipe.

Tab. 2. Values of numerical analyses of springback

\begin{tabular}{|l|l|l|l|}
\hline Material of pipe & $\begin{array}{c}\text { Value of bending } \\
\text { angle at the end of } \\
\left.\text { bending [ }{ }^{\circ}\right]\end{array}$ & $\begin{array}{c}\text { Value of bending } \\
\text { angle after } \\
\left.\text { springback [ }{ }^{\circ}\right]\end{array}$ & $\begin{array}{c}\text { Relative } \\
\text { difference } \\
{[\%]}\end{array}$ \\
\hline E235+N & 68.63 & 69.70 & 1.5 \\
\hline Kodur 260MC & 68.77 & 70.15 & 2 \\
\hline Steel 1.4313 & 70.25 & 74.16 & 5.3 \\
\hline
\end{tabular}

Results shown relationship between elasto-plastic material characteristic (type of strain-stress curve) and values of springback If characteristic of strain-stress curve is more steep (Fig. 2) then springback is bigger (steel 1.4313). When characteristic of strain-stress curve is shallow (Fig. 3, 4) springback is lower (steel Kodur 260MC and E235+N). This behaviour of elasto-plastic material during elastic return after unloading is obvious, but determination of springback after bending pipe process using analytical method is very difficult and time-consuming. Numerical results prove that FEM analysis of pipe bending process is a good tool to predict final degree of bending. It is important especially for precise bending process in mass production.

Difference between received results of bending angle from experiment and numerical analysis for steel $\mathrm{E} 235+\mathrm{N}$ is lower than $1 \%$.

\section{CONSLUSIONS}

Properly selected values of bending process using numerical simulations reduce preparation time and costs. FEM analysis of bending processes require of knowledge a stress-strain characteristic of material. Experimental verification of numerical results based on shape errors comparison gave good results. Expected behavior of elasto-plastic material depending on stress-strain curve character was numerically confirmed. Values of bending angle after springback obtained from experiment and numerical simulation are very close. These conclusions confirm that workedout FEM model can be used in engineering applications for simulation of ram-press pipe bending process for different kinds of steel.

\section{REFERENCES}

1. Dong L., Huang Y., Dong G.,Zhang Q., Liu G. (2015), Bending behavior modeling of unbonded flexible pipes considering tangential compliance of interlayer contact interfaces and shear deformations, Marine Structures, 42, 154-174.

2. Dong L., Tu S., Huang Y., Dong G., Zhang Q. (2015), A model for the biaxial dynamic bending of unbonded flexible pipes, Marine Structures, 43, 125-137.

3. Guarracino F., Walker A.C., Giordano A. (2008), Effects of boundary conditions on testing of pipes and finite element modeling, International Journal of Pressure Vessels and Piping, 86, 196-206.

4. Hao Y., Jinyuan Q., Sunting Y., Chenghang J., Lin W., Zhi-jiang J. (2016), Limit bending moment for pipes with two circumferential flaws under combined internal pressure and bending, International Journal of Mechanical Sciences, 106, 319-330.

5. Hu Z. (1998), Elasto-plastic solutions for spring-back angle of pipe bending using local induction heating, Journal of Materials Processing Technology, 102,103-108.

6. Korzemski J.W. (1971), Bending of thin-walled pipes (in Polish), Wydawnictwo Naukowo-Techniczne, Warszawa

7. Kuang Y., MorozovE.V., Ashraf M.A., ShankarK. (2015), Numerical analysis of the mechanical behaviour of reinforced thermoplastic pipes under combined external pressure and bending, Composite Structures, 131 453-461.

8. Li J., Zhou Ch., Cui P., He X. (2015), Plastic limit loads for pipe bends under combined bending and torsion moment, Int. J. of Mech. Sciences, 92, 133-145.

9. Menshykova M.,Guz I.A. (2014), Stress analysis of layered thickwalled composite pipes subjected to bending loading, International Journal of Mechanical Sciences, 88, 289-299.

10. Ottosen N.S., Ristinmaa M. (2005), The mechanics of constitutive modeling, Lund University, Sweden.

11. Sidun P. (2015), Modeling of plastic deformation during bending process at several levels (in Polish), MSC diploma work, supervisor A. Łukaszewicz, Bialystok University of Technology.

12. Vasilikis D., Karamanos S.A. (2012), Mechanical behavior and wrinkling of lined pipes, International Journal of Solids and Structures, 49, 3432-3446.

13. Xue J., Wang Y., Yuan D.(2015) A shear deformation theory for bending and buckling of undersea sandwich pipes, Composite Structures, 132, 633-643.

14. Zhao J., Yin J., Ma R., Ma L.X. (2011) Springback equation of small curvature plane bending, Sci China Technol Sci, 54(9), 2386-2396.

15. Zhao J., Zhan P., Ma R., Zhai R. (2014) Prediction and control of springback in setting round process for pipe-end of large pipe, International Journal of Pressure Vessels and Piping, 116, 58-62.

This paper was performed within a framework of S/WM/2/2013 realised in Bialystok University of Technology. 